\section{Laparoscopic Surgery: Do we really need a Deep Block?}

\section{Yasser Samhan ${ }^{1 \star}$ and Mohamed Shaaban $\mathrm{Ali}^{2}$}

${ }^{1}$ Department of Anesthesiology and Intensive Care, Theodor Bilharz Research Institute, Ministry of High Education and Scientific Research, Giza, Egypt

${ }^{2}$ Department of Anesthesia, College of Medicine, Assiut University, Assiut, Egypt

\section{Editorial}

The introduction of curare by Griffith into clinical practice in 1942 remains a breakthrough in the history of practice of anesthesia [1]. Although it has been used by Indians as an arrow poison as reported by Sir Walter Raleigh in 1595, yet Watterson and Brodie described the death from it as being due to respiratory paralysis in 1814, a finding confirmed by Claude Bernard in 1840 . The first true substrate available for clinical practice was called "Intocostrin" which was used in doses of $100 \mathrm{mg}$ to ensure muscle relaxation while the patient was breathing spontaneously [1]. Gradually with increased familiarity with these drugs evolved the "Liverpool technique" where high doses of muscle relaxants were used with $\mathrm{O}_{2} / \mathrm{N}_{2} \mathrm{O}$ hyperventilation and deep blocks started to develop [2].

To reach adequate inflation pressures during laparoscopic surgery, surgeons have always had the myth that deep muscle relaxation is an essential part of such technique. This myth grew even bigger with the introduction of low pressure laparoscopic surgery. Nowadays, there is a rising controversy about the level of neuromuscular block that should be achieved and maintained during laparoscopy. Depth of block can be graded as follows: Extreme block with Posttetanic Contraction (PTC) of zero; Deep (profound, extreme) block with PTC of 1 or more while Train of Four (TOF) count is zero; moderate block with TOF count of 1 to 3 while shallow block has a TOF of 4 with fade [3].

Such major debate appeared recently in the literatures about using deep or moderate block during laparoscopy surgery, and no conclusive evidence supports any of them. Deep muscle relaxation can improve surgical conditions especially during low pressure laparoscopic surgeries; however it is associated with postoperative residual curarization $[4,5]$.

"Corresponding author: Yasser Samhan, Department of Anesthesiology and Intensive Care, Theodor Bilharz Research Institute, Ministry of High Education and Scientific Research, Warak El-Hadar, Kornish El-Nile, Giza 12411, Egypt, Tel: +20 1222123524; Email: ysamhany@hotmail.com

Citation: Samhan Y, Ali MS (2017) Laparoscopic Surgery: Do we really need a Deep Block? J Clin Stud Med Case Rep 5: 048.

Received: January 02, 2018; Accepted: January 10, 2018; Published: January 24,2018
Deep relaxation with rocuronium cannot be used in all patients undergoing laparoscopic surgery especially those with renal or liver impairment [6,7]. In addition, reversal with an expensive drug like sugammadex limits its routine use. Although sugammadex enhances faster recovery after rocuronium, recurariaztion has been observed after its use in obese patients [8].

Recently, Baete et al., found no added benefit of deep muscle relaxation during bariatric surgery over moderate relaxation [8]. Others have observed marginal improvement in surgical conditions with deep relaxation with low pressure laparoscopic cholecystectomy. Despite this marginal improvement of surgical conditions with deep relaxation only $48 \%$ of surgeries were completed using such pressure [9].

More importantly, Chassard et al., as well as Chen et al., found that surgeons who were blinded by the anesthesia technique could not identify any difference in surgical conditions in the event of using or not using a muscle relaxant with TIVA during laparoscopic gynecological surgeries $[10,11]$.

Using single dose of rocuronium $0.6 \mathrm{mg} / \mathrm{kg}$, Paek et al., could manage laparoscopic pelvic surgeries under TIVA for around 100 minutes duration with adequate operating circumstances, even though at least the last 30 minutes were done without any residual effect of muscle relaxant [12]. It is also worth noting that the intraoperative use of muscle relaxants increases the incidence of awareness and interferes with the BIS readings $[13,14]$.

It is clear that the use of deep muscle relaxation during laparoscopic surgery is quite hazardous and necessitates the availability of sugammadex as the drug of choice for rocuronium reversal. Denying the patient from moving as a sign of awareness as well as interference with the actual BIS values is another pitfall for this technique. Omitting muscle relaxants completely from anesthesia still carries the hazards of coughing or straining during surgery with a suboptimal working surgical field. It also needs the use of a potent narcotic agent (remifentanil) to facilitate the ventilation of the patient.

Furthermore, quantitative neuromuscular monitoring is the cornerstone of the anesthetic technique during laparoscopic surgery to prevent residual curarization and maintenance of a moderate block (TOF count 1 to 3 ) seems to be an adequate practice until further studies proves any different approach to reach conclusive evidence for better patient care and proper use of hospital resources [4,5].

\section{References}

1. Griffith HR, Johnson GE (1942) The use of curare in general anesthesia. Anesthesiology 3: 418-20.

2. Gray TC, Halton J (1946) A milestone in anaesthesia? (d-tubocurarine chloride). Proc R Soc Med 39: 400-410.

3. Kopman AF, Naguib M (2015) Laparoscopic surgery and muscle relaxants: Is deep block helpful? Anesth Analg 120: 51-58.

4. Brull SJ, Murphy GS (2010) Residual neuromuscular block: Lessons unlearned. Part II: Methods to reduce the risk of residual weakness. Anesth Analg 111: 129-140. 
5. Murphy GS, Brull SJ (2010) Residual neuromuscular block: lessons unlearned. Part I: Definitions, incidence and adverse physiologic effects of residual neuromuscular block. Anesth Analg 111: 120-128.

6. Nonaka T, Fujimoto M, Nishi M, Yamamoto T (2013) The effect of rocuronium and sugammadex in hepatic tumor patients without preoperative hepatic impairment. Masui 62: 304-308.

7. Staals LM, Snoeck MM, Driessen JJ, van Hamersvelt HW, Flockton EA, et al. (2010) Reduced clearance of rocuronium and sugammadex in patients with severe to end-stage renal failure: A pharmacokinetic study. $\mathrm{Br} \mathrm{J}$ Anaesth 104: 31-39.

8. Baete S, Vercruysse G, Vander Laenen M, De Vooght P, Van Melkebeek J, et al. (2017) The Effect of Deep Versus Moderate Neuromuscular Block on Surgical Conditions and Postoperative Respiratory Function in Bariatric Laparoscopic Surgery: A Randomized, Double Blind Clinical Trial. Anesth Analg 124: 1469-1475.

9. Staehr-Rye AK, Rasmussen LS, Rosenberg J, Juul P, Lindekaer AL, et al. (2014) Surgical space conditions during low-pressure laparoscopic cholecystectomy with deep versus moderate neuromuscular blockade: A randomized clinical study. Anesth Analg 119: 1084-1092.
10. Chassard D, Berrada K, Tournadre J, Bouletreau P (1996) The effects of neuromuscular block on peak airway pressure and abdominal elastance during pneumoperitoneum. Anesth Analg 82: 525-527.

11. Chen BZ, Tan L, Zhang L, Shang YC (2013) Is muscle relaxant necessary in patients undergoing laparoscopic gynecological surgery with a ProSeal

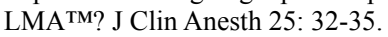

12. Paek CM, Yi JW, Lee BJ, Kang JM (2009) No supplemental muscle relaxants are required during propofol and remifentanil total intravenous anesthesia for laparoscopic pelvic surgery. J Laparoendosc Adv Surg Tech A 19: 33-37.

13. Gao JD, Zhao YJ, Xu CS, Zhao J, Huang YG, et al. (2012) Evaluation of entropy for monitoring the depth of anesthesia compared with bispectral index: A multicenter clinical trial. Chin Med J (Engl) 125: 1389-1392.

14. Forbes AR, Cohen NH, Eger EI $2^{\text {nd }}$ (1979) Pancuronium reduces halothane requirement in man. Anesth Analg 58: 497-499. 